\title{
Socio-economic profile of duck farmers and duck management practices in Rajshahi region
}

\author{
MB Alam ${ }^{1}$, ABMS Uddin ${ }^{2}$, MAZH Bablu ${ }^{3}$, MHK Kamaly ${ }^{4}$, MM Rahaman $^{5}$ \\ ${ }^{1}$ Rajshahi WASA, Rajshahi 6203, Bangladesh; 'Zila Parishad, Natore, Bangladesh; ${ }^{3}$ Upazila Agriculture Office, \\ Tanore, Rajshahi, Bangladesh; ${ }^{4}$ Ministry of Agriculture, Bangladesh Secretariat, Dhaka, \\ Bangladesh; ${ }^{5}$ Department of Agriculture Extension Education, University of Rajshahi, Rajshahi, Bangladesh
}

\begin{abstract}
The present study was conducted to determine the socio-economic profiles of the duck farmers and to investigate the management practices of duck farming and to identify the problems of duck farming in two upazilas of Rajshahi district namely: Bagmara and Tanore during the period from April to May 2012 by using a pre-tested questionnaire. Socio-economic profile of the duck farmers like age, education, family size, occupation, marital status, farm size, training received, annual income and management practices particularly housing, feeding, breeding, cleaning, disposal of diseased/dead birds, vaccination program, veterinary services followed by the farmers were investigated during the research. A total of 100 duck (50 from each upazila) were selected randomly for this study. The results reveal that most of the respondent farmers were young $(60 \%)$ having secondary level of education (69\%). Family size of the most of the farmers (57\%) were small (size 4.53 persons) and majority of the farmers $(75 \%)$ were marginal (0.021-020 hectare). Most of the farmers were medium income group (57\%) with mean annual income of Tk. 200500. About $42 \%$ farmers had training on farming of different duration ( 7 to 30 d). Highest proportion of the duck houses were made of tin-shed (74\%) having necessary floor space for ducks. The data obtained illustrated that majority of the farmers (74\%) used sufficient supplementary feed to their ducks. About $65 \%$ of the farmers reared Deshi ducks in their farms. Most of the farmers (70\%) cleaned their farm houses regularly. About $73 \%$ farmers separated their diseased duck from healthy ones. It was also found that most of the farmers (89\%) buried their dead ducks under soil. Data indicated that majority of the farmers (67\%) had partial idea about duck diseases. The highest proportion of the farmers $(72 \%)$ followed vaccination program strictly. About $71 \%$ farmers consulted with village doctor. Nearly $51 \%$ farmers had low level of knowledge about duck farming. In the present study 10 problems were identified out of which low price of duck meat and egg made ranked as most serious problems. If the problems are addressed properly, the duck raising could be more profitable business in Bangladesh.
\end{abstract}

Key words: Socio-economic profiles, management practices, duck farming, Rajshahi region

Bangladesh Animal Husbandry Association. All rights reserved. Bang. J. Anim. Sci. 2012. 41 (2): 96-105

\section{Introduction}

As a species next to chicken, duck production plays an important role in the rural economy of Bangladesh. According to a report of Food and Agricultural Organization, the position of Bangladesh with respect to duck meat and egg production is $11^{\text {th }}$ and $4^{\text {th }}$ respectively among the Asian countries (Pingel 2011). Duck farm serves dual purpose - egg and meat. Duck comprises of about $16 \%$ (42.68 million) of the total poultry population ( 270.71 million), occupying second place next to chicken in the production of table eggs in the country (Bangladesh Economic Review 2010). It contributes a major source of animal protein in Bangladesh. Like chicken duck provides hard-cash income and creates employment opportunities for the rural farmers and landless women and could be produced within a short time at reasonable cost. Duck production has some unique advantages such as: 1)Duck rearing is profitable and simple in management, 2) Ducks are less hazardous bird (3) They have more disease resistance capacity than other poultry birds, (4) They have longer economic egg-production life, (5) Duck eggs are heavier and get a better price, 6) Ducks are good forager and hence need less food(7) Duck meat is very delicious and is preferred by the people, (8) The birds do not need elaborate housing and (9) Ducks act as biological means of pest control by eating snails and other crop pests. There are good number of beels, ponds and other natural wetlands facilitating duck rearing in Rajshahi. For the above advantages, duck production is getting 
popularity day by day in this region. Rajshahi is a northern district of Bangladesh situated on the bank of the river Padma. So, a great potentiality of duck raising exists in northern areas of Bangladesh like Rajshahi. In this investigation an attempt was made to study the existing duck management system in selected areas of Rajshahi district. The objectives of the study were to determine the socio-economic profiles of the duck farmers, to investigate the present management practices of duck farming and to identify the problems of duck farming.

\section{Materials and Methods}

Two upazilas in the district of Rajshahi namely: Bagmara and Tanore were selected purposively due to comparatively higher concentration of duck farms in these areas. Another reason was- that no study of this kind was conducted previously in this region. According to the information supplied by District Livestock officer, Rajshahi, there are 160 duck farms (Bagmara 85 and Tanore 65) in the study area. A total of 100 farmers ( 50 from each upazila) (46\% of total farms) constituted the sample of the study. For the collection of primary data, direct interview method was followed using pre-tested questionnaire. Data were collected both from primary and secondary sources. The secondary data sources constituted government documents, related literatures, books, journals, newspapers, articles, theses, and web sites. The data were collected during April to May 2012 by trained data collectors, subsequently processed and analyzed according to the objectives of the study. Descriptive statistics such as mean, percentage, range, standard deviation and ranking were used to describe the indicators of the study. The data were analyzed by using the SPSS software.

Measurement of socio-economic profile of the duck farmers and management practices followed in duck farms are described below:

\section{Age}

Age of a respondent was measured in terms of year from birth to time of taking interview. A unit score was assigned for each year of one's age. On the basis of age (years) the farmers of the study area were classified into three groups namely: young, middle-aged and old.

\section{Education level}

Education is defined as a process of changing human behavior in a desired direction. It was measured in terms of one's year of schooling. One score was given for passing each level in an educational institution. According to the level of education the farmers were classified into three categories namely: primary, secondary and above secondary.

\section{Family size}

The family size was measured by the total number of members in the family of a respondent. The family members included the respondent him/herself, wife and husband, children and other dependent members who live and eat together. A unit score was assigned for each member of the family. On the basis of the number of family members, the respondent farmers were classified into three categories namely: small, medium and large.

\section{Occupation}

Occupation is a means or ways by which a man earns some money for his livelihood. The respondent under investigation has various occupations other than duck farming activities. These are- (1) duck farming, (2) agriculture, (3) service and (4) business.

\section{Marital status}

The marital status of the respondent farmers was four types namely: married, unmarried, divorced and others (widow, abundant etc.)

\section{Farm size}

The farm size was measured by the area of raised land in which the household of the respondent had its entire dwelling including homestead, area under cultivation and others (Sarker 2005). It was expressed in hectare. The total area of land thus obtained has been considered as farm size of the respondent. Depending on the farm size, the duck farmers were classified into five categories namely: landless, marginal, small, medium and large followed by the rules of Department of Agriculture Extension, Government of the People's Republic of Bangladesh.

\section{Training received}

Training brings a positive change in working efficiency of human life. Training received was measured by the total number of day attended by the respondent in different training programs in his life arranged by any organization. A score of 1 (one) was given for each day of training attended (Sarker 2005). On the basis of training score, the respondent farmers were classified into four categories namely: No training, short training, moderate training and long training. 


\section{Duck farming in Rajshahi region}

\section{Annual family income}

Annual family income of a respondent was measured by taking the sum of income earned in a year by the respondent himself and other members of the family in a year from different sources like crop, livestock, fisheries and some other non-agricultural sources (business, service etc.). It was expressed in thousand ('000') Taka. Depending on the level of income the farmers were classified into three categories namely: low, medium and high income.

Management is a combined effort of daily activities in any institution or any organization or any factory or any farm. In duck farms, management includes housing, staff position, feeding, sanitation, and disease control in poultry farm. The measurement of management practices is given below.

\section{Housing}

Type of house: Total housing type was three-(1) soil-made (2) bamboo-straw-made, and (3) tinshed.

Floor space for ducks: The standard floor space for ducks is 1.5-2.0 square feet. On the basis of standard floor space the respondents were classified into two categories namely: sufficient and insufficient.

Ventilation: Ventilation is of two types. One is sufficient and another is insufficient. Depending on ventilation facilities the farm houses were classified into two categories namely: sufficient and insufficient ventilation.

\section{Feeding management}

Sources of feed: There were two types of feed used in duck farm. These were-(1) natural (scavenging) and (2) supplemented feed.

Quantity of feed: Quantity of feed supply in duck farm is of two types. One is sufficient and another is insufficient.

Use of feed ingredients: There were three types of feed ingredients used in the sample duck farm of the study area namely: (1) mixed feed, (2) paddy and wheat and (3) paddy alone

\section{Breed used in duck farm}

There were mainly three types of duck breed in the study area. These were: Deshi, Khaki Campbell and Zinding.

\section{Prevention and control of Disease}

Cleaning of duck house: The respondent farmers were asked whether they clean their poultry farm regularly or not. The responses were of three types-(1) regular cleaning, (2) irregular cleaning and (3) not at all.

Disposal of Diseased ducks: The respondent farmers were asked whether they separate diseased duck or not. The responses were two types namely-(1) yes and (2) no.

Disposal of dead ducks: In the study area the process of disposal of dead duck is of two types namely: buried and thrown away.

Farmers' idea about duck disease: The respondent was asked whether they have idea about duck disease or not. The answers were two types namely: clear idea and partial idea.

Vaccination program followed in duck farm: The respondent was asked whether they follow regular vaccination program in their duck farm or not. The answers were two types namely: regular, irregular and not at all.

Veterinary services during disease outbreak: The respondents were asked which type of veterinary services they take during the outbreak of disease in their duck farm. The types of treatments were (1) veterinary doctor, (2) village doctor and (3) no veterinary services.

\section{Knowledge about duck farming}

The knowledge of duck farming of an individual farmer refers to the level of awareness, understanding and skill of various aspects of duck farm practices. It was measured by computing a duck farming knowledge score based on some questions on different aspects of duck farming. The questions included items on remembering, understanding, applying, analyzing, evaluating and creating. A score of 2 (two) was assigned for a question of remembering and understanding, Questions for rest four dimensions were assigned a score of 3 (three). Each item contains 5 questions. Full marks was given for satisfactory answer from the respondents; half or two-third mark for partial correct answer and zero mark for wrong or no answer. In this way the total score was measured which could be varied from 0 to 80 . Zero indicates no knowledge while 80 indicates highest knowledge about duck farming. Depending on obtained score of knowledge the participant farmers were classified into three categories namely: low, medium and high level of knowledge. 


\section{Ranking the constraints to duck farming}

The participant duck farmers were asked to give weight on 10 selected problems depending on their intensity (low $=1$, medium $=2$ and high=3). Final rank order of the selected problems was done based on total weighted score of each problem. Total score was determined by the formula followed by Mozumdar et al. (2009). The formula is given below.

Total score $=$ Number of respondents $\times$ Intensity of problem (High + Medium + Low)

$$
=\mathrm{n}_{3} \times 3+\mathrm{n}_{2} \times 2+\mathrm{n}_{1} \times 1
$$

Where, $n_{3}, n_{2}$ and $n_{1}=$ Number of respondents giving high (3), medium (2) low weight (1) respectively.

On the basis of total weighted score these problems were finally ranked as, $1^{\text {st }}, 2^{\text {nd }}, 3^{\text {rd }}, 4$ th and so on respectively out of 10 .

\section{Results and Discussion}

Socio-economic profiles of the respondent farmers are described below:

\section{Age}

The mean age of the farmers was 34.48 years with standard deviation 8.94. On the basis of age (years) the farmers of the study area were classified into three groups namely: young, middle-aged and old. Data presented in Table 1 indicate that the majority of the farmers $(60 \%)$ in the study area were young followed by middleaged $(38 \%)$ and old $(2 \%)$ respectively.

\section{Education}

Education scores (schooling year) of respondent farmers ranged from 3 to 14 with mean 7.40. The standard deviation value was 3.05 for the duck farmers of the study area. According to the level of education the farmers were classified into three categories namely: primary, secondary and above secondary. Data presented in Table 1 express that the highest proportion of farmers (69\%) belonged to secondary level followed by primary (23\%) and above secondary $(8 \%)$ level of education respectively.

\section{Family size of the farmers}

The family size of the participant farmers ranged from 2.00 to 7.00 numbers for the duck families. The mean family size of the participants was 4.53 with standard deviation 0.82 . On the basis of the number of family members, the respondent farmers were classified into three categories namely: small, medium and large. Data show that small family size was the highest (57\%) followed by medium ( $31 \%$ ) and large family $(12 \%)$. It is also seen from the table that average family size (4.53) was smaller than that of national level (4.90) (BBS 2001).

\section{Occupation}

The occupation of the participant farmers are shown in Table 1. From the table it is evident that most of respondent farmers $(50 \%)$ had farming as their main occupation followed by agriculture $(32 \%)$, business $(13 \%)$ and service $(5 \%)$. The participant duck farmers had some subsidiary occupation which helped them in earning some extra income.

\section{Marital status}

Marital status of the farmers is shown in Table 1. From the data presented in the table, it is seen that majority of the duck farmers $(68 \%)$ were married followed by unmarried (17\%), divorced $(13 \%)$ and others (widow, separated etc.) $(2 \%)$.

\section{Farm size}

The farm size of the respondent farmers ranged from 0.03 hectare to 2.00 hectare. The mean farm size was 0.18 hectare with standard deviation 0.24. Depending on the farm size the duck farmers were classified into five categories followed by the rules of Department of Agriculture Extension, Government of the People's Republic of Bangladesh as shown in Table 1. Data furnished in Table 1 represent that the highest proportion of the respondent $(75 \%)$ were marginal farmers followed by small farmers (15\%) and medium farmers $(10 \%)$. Proportion of large and landless farmers was zero.

\section{Training received}

Sometimes local Livestock Department and NGOs arrange training for the poultry and dairy farmers. The information about training received by the respondent farmers is shown in Table 1 . On the basis of training score the respondent farmers were classified into four categories namely: no training, short training, moderate training and long training. Data presented in Table 1 indicate that highest proportion (58\%) of the farmers had no training. Only $22 \%, 17 \%$ and $3 \%$ farmer had moderate, short and long training respectively. However, average duration of training of the above mentioned farmers were $3.92 \mathrm{~d}$. 


\section{Duck farming in Rajshahi region}

\section{Annual income}

Annual income of the respondent farmers ranged from Tk. 60000 to Tk. 360000. The mean annual income of the farmers was Tk. 205000 with standard deviation Tk. 74010. Depending on the level of income, the farmers were classified into three categories namely: low, medium and high income. From Table 1 it is seen that most of the farmers $(57 \%)$ were medium income group followed by low (32\%) and high (11\%) income group.

Duck housing system in the study area are described below:

\section{Type of house}

In duck farming, proper housing is an important thing. Houses protect duck from bad weather and predator animals. In the study area, mainly three types of duck houses were found which are shown in Table 2. From the table, it is evident that most of the houses were tin-shed $(74 \%)$ followed by bamboo-straw made (15\%) and soil made (11\%). Rahman et al. (2009) found almost similar result regarding type of duck houses in coastal region of Noakhali and Lakshimpur district of Bangladesh. This might be the due to the fact that tin-shed houses are permanent and long lasting. Cost involvement is not so high. So, most of the participant farmers were encouraged to make low cost shelter for their ducks. Another reason was that the tin-shed houses are more secured and hygienic for duck.

\section{Floor space for ducks}

Floor space is an important factor for duck farming. Higher stocking density hampers growth performance of poultry (Mendes et al. 2004). The standard floor space for ducks is 1.5-2.0 square feet. On the basis of standard floor space the respondents were classified into two categories namely: sufficient and insufficient (Table 2). In the study area most of the farmers ensured sufficient floor space ( $75 \%$ ) for their ducks. Only $25 \%$ farmers did not maintain standard floor space due to poor knowledge and management inefficiency in duck farming.

\section{Ventilation in duck house}

Ventilation permits natural air and light in the duck houses that enhance growth of duck. It should be used as a major management tool to provide the optimum healthy environment for duck. Due to lack of testing facilities with modern equipments, natural ventilation (sufficient air movement) was observed by open eyes. However, depending on ventilation facilities the farm houses were classified into two categories namely: sufficient and insufficient ventilation. From the data furnished in Table 2 it was seen that most of the duck (74\%) houses had sufficient ventilation. The ventilation facilities of rest of the duck houses were insufficient $(26 \%)$.

\section{Feeding management}

Feeding management is the most important factor in duck farming. Because, feed cost is the highest cost among all other production costs. Efficient management in feeding duck saves production cost that increases net return from duck farm. However, feeding management is described in the following sub-section.

\section{Sources of feed}

There were two sources of feed considered for feeding ducks in the study area. These were: natural (scavenging) and supplemental feed. Supplemental feed was produced by the farmers themselves or collected by the farmers from the market. Duck farmers collected various feed ingredients (paddy, wheat bran, broken rice, rice polish etc.) and prepared a mixed feed in their farm premises. The respondent farmers opined that in mixed feed system they were confirmed that all the feed ingredients and nutrients were present in mixed feed. But in scavenging feeding system they were not sure about the presence of all nutrients in required proportion. However, most of the farmers (74\%) gave supplementary feed to their ducks (Table 3 ). The rest $26 \%$ farmers depended only on natural feed. Rahman et al. (2009) observed somewhat different result on feed supplementation. They showed that $61.5 \%$ farmers gave supplementary feed (additional feed) to their ducks in the coastal areas. The reason might be that coastal region is a good source of natural feed on which a considerable portion of farmers (38\%) were depended.

\section{Quantity of feed}

Quantity of feed is very important factor in duck farm management because sufficient feed is required for optimum growth. On the other hand, misuse of feed increases production cost. So, standard amount of feed should be supplied regularly. The amount of feed per duck per day depends on age. It starts from 20-30 gram feed (at the age $1^{\text {st }}$ week) $d$ which increases gradually to 110-130 gram feed per duck per day after laying commences. Depending on the quantity of feed 
supplied by the farmers to their ducks daily, the feed sufficiency was recorded. Table 3 represents the feed sufficiency in duck farms under study. From the table, it is illustrated that most of the farmers $(71 \%)$ supplied sufficient feed to their ducks. Only $29 \%$ farmers did not supply sufficient feed. This might be due to lack of proper knowledge about duck farming. Another reason might be that these farmers had a tendency to earn more profit with minimum cost.

\section{Use of feed ingredients}

Good quality feed ensures optimum growth. Use of various feed ingredients improves the quality of feed. Table 3 represents the use of feed ingredients in the ration of duck. From the table it is illustrated that most of the farmers (64\%) supplied mixed feed to their ducks followed by paddy $(20 \%)$ and wheat and paddy alone (16\%). This might be due to lack of proper knowledge about feeding management in duck farming.

\section{Type of breed used in duck farm}

Type of breed used in the duck farm is shown in Table 4. The table indicates that most of the farmers reared Deshi duck (65\%) followed by Khaki Campbell $(23 \%)$ and Jinding (12\%) in their farms. Some farmers collected day-old ducklings from dealers who are agents of various hatcheries while some other produced duckling in their houses. Highest availability of Deshi duck all over Bangladesh excepting Haor Area (Netrokona, Kishoreganj and Sunamganj district) was reported by Department of Fisheries and Livestock Information in J une 2011.

\section{Cleaning of farm house}

Regular cleaning is a part and parcel of duck farm management. Regular cleaning protects the farm houses from outbreak of disease. It also keeps the farm environment healthy. Table 5 represents the cleaning practices followed in the farm houses of the study area. From the table, it is found that most of the farmers (70\%) cleaned their farm houses regularly. On the other hand, $21 \%$ farmers did not clean their farms regularly. A few portions of farmers ( $9 \%$ ) never cleaned their farm houses. I rregular cleaning and failure to cleaning might be due to lack of knowledge and/or a sort of negligency.

\section{Disposal of diseased ducks}

Disease may occur at any time in any duck farm, so disposal of diseased duck is very important. If diseased duck is separated at once from the flock and proper care is taken then the whole farm will be protected from contagious diseases. All duck farms should maintain this rule strictly. But slight deviation of this rule was found in the study area. Table 5 indicates that majority of the farmers (73\%) followed this rule. Only $17 \%$ farmers did not separate their diseased ducks from the healthy ones. The rest $10 \%$ farmers utilized their diseased ducks for domestic consumption.

\section{Disposal of dead ducks}

Deaths of ducks are normal phenomena in duck farm. Dead duck should be disposed of very carefully. It is a common practice to burry or burns the dead duck. During burning bad smell is spread out. For this reason, the system of burying the dead duck is widely used. In most cases (89\%), this principle was followed in the study area (Table 5). But $11 \%$ farmers of the study area did not follow this rule. They threw away the dead ducks outside. The reason is the lack of proper knowledge. The lack of awareness on the impact of throwing dead birds elsewhere might be a reason.

Table 1. Socio-economic profile of the participant farmers

\begin{tabular}{|c|c|c|c|}
\hline Characteristics & Category & $\%$ & Mean \\
\hline \multirow{3}{*}{ Age (year) } & Young (up-to 35) & 60 & \multirow{3}{*}{$\begin{array}{l}34.48 \\
\pm 8.94\end{array}$} \\
\hline & Middle-aged (36-50) & 34 & \\
\hline & Old (Above 50) & 6 & \\
\hline \multirow{3}{*}{$\begin{array}{l}\text { Education } \\
\text { (schooling } \\
\text { year) }\end{array}$} & Primary (1-5) & 23 & \multirow{3}{*}{$\begin{array}{c}7.40 \\
\pm 3.05\end{array}$} \\
\hline & Secondary (6-10) & 69 & \\
\hline & $>$ secondary $(>10)$ & 8 & \\
\hline \multirow{3}{*}{$\begin{array}{l}\text { Family } \\
\text { size(no.) }\end{array}$} & Small (Up-to 4) & 57 & \multirow{3}{*}{$\begin{array}{c}4.53 \\
\pm 0.82\end{array}$} \\
\hline & Medium (5-6) & 31 & \\
\hline & Large (Above 6) & 12 & \\
\hline \multirow{4}{*}{ Occupation } & Agriculture & 32 & \multirow{4}{*}{$=$} \\
\hline & Service & 5 & \\
\hline & Business & 13 & \\
\hline & Farming & 50 & \\
\hline \multirow{4}{*}{ Marital status } & Married & 68 & \multirow{4}{*}{--} \\
\hline & Unmarried & 17 & \\
\hline & Divorced & 13 & \\
\hline & Others & 2 & \\
\hline \multirow{5}{*}{$\begin{array}{l}\text { Farm size } \\
\text { (hectare) }\end{array}$} & Landless (upto-0.02) & 0 & \multirow{5}{*}{$\begin{array}{c}0.18 \\
\pm 0.24\end{array}$} \\
\hline & Marginal $(0.0210 .20)$ & 75 & \\
\hline & Small (0.21-1.00) & 15 & \\
\hline & Medium (1.01-3.00) & 10 & \\
\hline & Large (Above 3.00) & 0 & \\
\hline \multirow{4}{*}{ Training (day) } & No training & 58 & \multirow{4}{*}{$\begin{array}{l}3.92 \\
7.28\end{array}$} \\
\hline & Short (1-7) & 22 & \\
\hline & Moderate (8-15) & 17 & \\
\hline & Long (> 15) & 3 & \\
\hline \multirow{3}{*}{$\begin{array}{l}\text { Annual } \\
\text { income (Tk.) }\end{array}$} & Low (60-106) & 32 & \multirow{3}{*}{$\begin{array}{l}205000 \\
\pm 74010\end{array}$} \\
\hline & Medium (107-150) & 57 & \\
\hline & High (151-360) & 11 & \\
\hline
\end{tabular}




\section{Duck farming in Rajshahi region}

\section{Farmers' I dea about duck disease}

The level of idea of the respondent farmers about duck diseases is shown in Table 5. The data contained in the table indicate that major portion of the farmers $(67 \%)$ had partial idea about duck diseases. On the other hand, 33\% farmers had clear idea about duck diseases. The reason behind it is lack of training facilities for the farmers.

\section{Vaccination program followed in duck farm}

Prevention is better than cure. This popular principle is mostly used in duck farms. All the duck farmers have to follow strictly a vaccination schedule. Vaccination protects the birds from diseases and saves production cost. The information collected on vaccination program followed by the respondent farmers is shown in Table 5. From the table it is evident that about $72 \%$ farmers vaccinated their ducks regularly. On the other hand, $18 \%$ farmers did not follow vaccination program regularly. It is interesting to note that a few numbers of farmers (10\%) were very much reluctant in maintaining vaccination program. They never use vaccine in their farms. This might due to the fact that they have no training on poultry farming.

\section{Veterinary services during disease outbreak}

When disease occurs in the farm, the duck farmers have to need services from veterinary doctors. But in the study area most of the farmers $(71 \%)$ took veterinary services from village doctor (Table 5). Only $18 \%$ farmers consulted directly with veterinary doctors for the treatment of their diseased ducks. There were some farmers who never consulted with doctor (11\%) for medication of their diseased ducks. The reason might be that for consultation with veterinary doctor the farmers had to come at upazila veterinary hospital and pay fee to the doctors, which was costly. In addition, it is also time consuming for them.

Table 2. Duck housing system

\begin{tabular}{|c|c|c|c|c|c|}
\hline \multirow{2}{*}{ Housing } & \multicolumn{2}{|c|}{ Bagmara $(n=50)$} & \multicolumn{2}{|c|}{ Tanore $(n=50)$} & \multirow{2}{*}{$\begin{array}{l}\text { Mean }(n=100) \\
\text { Percent }\end{array}$} \\
\hline & Frequency & Percent & Frequency & Percent & \\
\hline \multicolumn{6}{|l|}{ Type } \\
\hline Tin-shed & 36 & 72 & 38 & 76 & 74 \\
\hline Bamboo-straw made & 8 & 16 & 7 & 14 & 15 \\
\hline Soil and others made & 6 & 12 & 5 & 10 & 11 \\
\hline Total & 50 & 100 & 50 & 100 & 100 \\
\hline \multicolumn{6}{|l|}{ Floor space } \\
\hline Sufficient & 38 & 76 & 37 & 74 & 75 \\
\hline Insufficient & 12 & 24 & 13 & 26 & 25 \\
\hline Total & 50 & 100 & 50 & 100 & 100 \\
\hline \multicolumn{6}{|l|}{ Ventilation } \\
\hline Sufficient & 38 & 76 & 36 & 72 & 74 \\
\hline Insufficient & 12 & 24 & 14 & 28 & 26 \\
\hline Total & 50 & 100 & 50 & 100 & 100 \\
\hline
\end{tabular}

Table 3. Duck feeding management

\begin{tabular}{llllll}
\hline \multirow{2}{*}{ Feeding } & \multicolumn{2}{l}{ Bagmara $(\mathrm{n}=50)$} & \multicolumn{2}{l}{ Tanore $(\mathrm{n}=50)$} & Mean $(\mathrm{n}=100)$ \\
\cline { 2 - 6 } & Frequency & Percent & Frequency & Percent & Percent \\
\hline Sources of feed & 12 & 24 & 14 & 28 & 26 \\
Only Scavenging & 38 & 76 & 36 & 72 & 74 \\
Scavenging and supplementation & 50 & 100 & 50 & 100 & 100 \\
Total & & & & & \\
\hline Quantity of feed & 33 & 66 & 38 & 76 & 71 \\
Sufficient & 17 & 34 & 12 & 24 & 29 \\
Insufficient & 50 & 100 & 50 & 100 & 100 \\
Total & & & & & \\
\hline Feed Ingredients & 11 & 22 & 9 & 18 & 20 \\
Paddy & 9 & 18 & 7 & 14 & 16 \\
Wheat + paddy & 30 & 60 & 34 & 68 & 64 \\
Mixed feed & 50 & 100 & 50 & 100 & 100 \\
Total & & & & & \\
\hline
\end{tabular}




\section{Knowledge about duck farming}

The level of knowledge of farmers about duck farming is shown in Table 6. Depending on obtained score of knowledge, the participant farmers were classified into three categories namely: low, medium and high level of knowledge. Data presented in Table 6 show that the highest proportion of farmers had low (50\%) knowledge followed by medium (32\%) and high (18\%) level of knowledge about duck farming. The mean score of knowledge was 56.08 with standard deviation 6.53 in the study area. Lack of sufficient training facilities might be the reason for highest proportion of the farmers having low knowledge about duck farming.

Table 4. Type of breed used in duck farm

\begin{tabular}{lccccc}
\hline Breed & \multicolumn{2}{c}{$\begin{array}{c}\text { Bagmara } \\
(\mathrm{n}=50)\end{array}$} & \multicolumn{2}{c}{$\begin{array}{c}\text { Tanore } \\
(\mathrm{n}=50)\end{array}$} & $\begin{array}{c}\text { Mean } \\
(\mathrm{n}=100)\end{array}$ \\
\cline { 2 - 6 } & Freq. & $\%$ & Freq. & $\%$ & $\%$ \\
\hline Deshi & 33 & 66 & 32 & 64 & 65 \\
KC & 10 & 20 & 13 & 26 & 23 \\
Zinding & 7 & 14 & 5 & 10 & 12 \\
\hline Total & 50 & 100 & 50 & 100 & 100 \\
\hline KC, Khaki Campbell & & &
\end{tabular}

\section{Problems in Duck Farming}

On the basis of total weighted score these problems were finally ranked as, $1^{\text {st }}, 2^{\text {nd }}, 3^{\text {rd }}, 4$ th and so on problem respectively out of 10 . Lower price of duck egg and meat ( $1^{\text {st }}$ problem), higher price of feed ( $2^{\text {nd }}$ problem) and lack of training ( $3^{\text {rd }}$ problem) were found to be the three main problems in duck farming in the study area (Table 7 ). Most of the farmers ( $85 \%)$ opined that lower price of duck products (meat and egg) greatly affect profit margin from duck farming and they ranked this problem as $1^{\text {st }}$ out of 10 selected problems. Rahman (2009) also observed higher price of feed and lower price of duck meat and egg as vital problems in coastal area. About $77 \%$ and $75 \%$ farmers identified that higher price of feed and lack of training respectively as very serious problems for their business. Outbreak of disease, inadequate veterinary services, irregular supply of duckling, lack of sufficient capital price fluctuation of duck egg, problem of theft, and environment pollution were other important problems which were ranked as $4^{\text {th }}, 5^{\text {th }}, 6^{\text {th }}, 7^{\text {th }}$, $8^{\text {th }}, 9^{\text {th }}$ and $10^{\text {th }}$ problems respectively out of 10 . Though it was observed that outbreak of disease is an important problem in poultry sector especially in chicken farming (Roy 2000) but duck farmers of the study area ranked it as comparatively less serious problem $\left(4^{\text {th }}\right)$, because ducks are comparatively more resistant to diseases than chicken. Mahmud (1998) reported lower price of duck meat and egg, lack of credit, scarcity of feed in dry season, lack of proper treatment and medicine etc. were serious problem in duck farming in Haor region of Bangladesh.

\section{Suggestions for solving the problems}

To overcome the existing problems in duck farming and to make this business more profitable some suggestions were made based on the comments of the respondent farmers, duck related businessmen and livestock experts. The suggestions were:

\section{1) To reduce feed price}

Duck farming is one of the potential components of poultry industry in Bangladesh. So, for the national interest, the government should provide financial support to the farmers. Since most of the farmers complained about higher price of feed and day-old-chicks, the government intervention is needed to stable the market of production inputs in the study area. Good number of feed mills and hatcheries from where poultry farmers can purchase feed and chicks with reasonable price should be established through government and non-government initiatives.

\section{2) Maintaining stability in the market price}

Low price of meat and egg and its frequent fluctuations discourage the duck farmers and the related businessmen. Price stabilization should be ensured for the producers and other stakeholders. The smuggling of eggs from neighboring country should be strictly prohibited for the interest of thousands of duck farmers.

\section{3) Providing regular training for the farmers}

Since most of the farmers had low technical knowledge about duck farming, intensive training on farm management, duck diseases and its control should be provided by Department of Livestock Services. So, short training programs on these topics may be arranged by government and non-government authority. If training is provided properly, good management will be ensured that will make duck farming more profitable.

\section{4) Ensuring veterinary services}

In order to provide necessary veterinary services to the duck farmers, the government should establish new veterinary care centers with adequate machineries, vaccines, medicines and technical staffs, so that they can provide free veterinary services to the farmers. 

Duck farming in Rajshahi region

Table 5. Prevention and control of diseases in farm house

\begin{tabular}{|c|c|c|c|c|c|}
\hline \multirow{2}{*}{ Measures } & \multicolumn{2}{|c|}{ Bagmara $(n=50)$} & \multicolumn{2}{|c|}{ Tanore $(n=50)$} & \multirow{2}{*}{$\begin{array}{l}\text { Mean }(n=100) \\
\text { Percent }\end{array}$} \\
\hline & Frequency & Percent & Frequency & Percent & \\
\hline \multicolumn{6}{|l|}{ Cleaning practice } \\
\hline Regular & 34 & 68 & 36 & 72 & 70 \\
\hline Irregular & 10 & 20 & 11 & 22 & 21 \\
\hline Not at all & 6 & 12 & 3 & 6 & 9 \\
\hline Total & 50 & 100 & 50 & 100 & 100 \\
\hline \multicolumn{6}{|l|}{ Diseased ducks } \\
\hline Separation and treatment & 35 & 70 & 38 & 76 & 73 \\
\hline No separation & 9 & 18 & 8 & 16 & 17 \\
\hline Consumed & 6 & 12 & 4 & 8 & 10 \\
\hline Total & 50 & 100 & 50 & 100 & 100 \\
\hline \multicolumn{6}{|l|}{ Dead birds } \\
\hline Buried & 46 & 92 & 43 & 86 & 89 \\
\hline Thrown away & 4 & 8 & 7 & 14 & 11 \\
\hline Total & 50 & 100 & 50 & 100 & 100 \\
\hline \multicolumn{6}{|l|}{ I dea about disease } \\
\hline Clear idea & 15 & 30 & 18 & 36 & 33 \\
\hline Partial idea & 35 & 70 & 32 & 64 & 67 \\
\hline Total & 50 & 100 & 50 & 100 & 100 \\
\hline \multicolumn{6}{|l|}{ Vaccination } \\
\hline Regular & 34 & 68 & 38 & 76 & 72 \\
\hline Irregular & 10 & 20 & 8 & 16 & 18 \\
\hline Not at all & 6 & 12 & 4 & 8 & 10 \\
\hline Total & 50 & 100 & 50 & 100 & 100 \\
\hline \multicolumn{6}{|l|}{ Veterinary services } \\
\hline Veterinary doctor & 10 & 20 & 8 & 16 & 18 \\
\hline Village doctor & 34 & 68 & 37 & 74 & 71 \\
\hline No consultation & 6 & 12 & 5 & 10 & 11 \\
\hline Total & 50 & 100 & 50 & 100 & 100 \\
\hline
\end{tabular}

Table 6. Knowledge level of farmers about duck farming

\begin{tabular}{|c|c|c|c|c|c|c|}
\hline \multirow[t]{2}{*}{ Knowledge level } & \multicolumn{2}{|c|}{ Bagmara $(n=50)$} & \multicolumn{2}{|c|}{ Tanore $(n=50)$} & \multicolumn{2}{|c|}{$\operatorname{Mean}(n=100)$} \\
\hline & Frequency & Mean \pm SD & Frequency & Mean \pm SD & Frequency & Mean \pm SD \\
\hline Low-40-50 & $24(48)$ & $56.86 \pm 6.61$ & $26(52)$ & $55.31 \pm 6.45$ & $50(50)$ & $56.08 \pm 6.53$ \\
\hline Medium-51-60 & $18(36)$ & & $14(28)$ & & $32(32)$ & \\
\hline High-61-70 & $8(16)$ & & $10(20)$ & & $18(18)$ & \\
\hline Total & $50(100)$ & & $50(100)$ & & $100(100)$ & \\
\hline
\end{tabular}

Figures in parenthesis indicate the percentage values

Table 7. Problems faced by duck farmers

\begin{tabular}{lccccc}
\hline Problems & \multicolumn{3}{c}{ Intensity of problems } & Total score & Rank order \\
\cline { 2 - 4 } & High(3) & Medium(2) & Low(1) & & \\
\hline Lack of sufficient capital & $56(56)$ & $27(27)$ & $17(17)$ & 239 & 7 th \\
High price of feed & $77(77)$ & $13(13)$ & $10(10)$ & 267 & $2^{\text {nd }}$ \\
Low price of duck egg and meat & $85(85)$ & $15(15)$ & $00(00)$ & 285 & $1^{\text {st }}$ \\
Outbreak of disease & $55(55)$ & $45(45)$ & $00(00)$ & 255 & $4^{\text {th }}$ \\
Inadequate veterinary services & $67(67)$ & $20(20)$ & $13(13)$ & 254 & 5 th \\
Lack of training & $75(75)$ & $15(15)$ & $10(10)$ & 265 & $3^{\text {rd }}$ \\
Irregular supply of duckling & $55(55)$ & $38(38)$ & $7(7)$ & 248 & $6^{\text {th }}$ \\
Price fluctuation of duck egg & $30(30)$ & $50(50)$ & $20(20)$ & 210 & $8^{\text {th }}$ \\
Problem of theft & $28(28)$ & $47(47)$ & $25(25)$ & 203 & $9^{\text {th }}$ \\
Pollution of environment & $17(17)$ & $20(20)$ & $63(63)$ & 154 & $10^{\text {th }}$ \\
\hline
\end{tabular}

Figures in parenthesis indicate the percentage values 


\section{5) Regular supply of ducklings}

In case of non-availability of ducklings at the time of need, proper steps should be taken by the government to give incentives to private hatcheries to continue their production and supply of ducklings throughout the country.

\section{6) Sufficient credit supply}

To solve the insufficiency of working capital, the government and private banks and other financial institutions should grant credit to the duck farmers and related businessmen on easy terms and conditions. This type of financial support will help the farmers and other stakeholders to expand their business. The respondent farmers will be able to buy modern equipments and make better housing facilities for their birds.

\section{7) Prevention and control of diseases}

Since disease infestation appeared to be severe problem causing mortality of ducks, necessary preventive measures should be taken thorough vaccination program. All types of duck vaccines should be made available at the door steps of the farmers. Preparation of duck vaccines is not so costly for the government. So, government can supply vaccines to the farm owners at minimum price.

\section{Conclusion}

Socio-economic profile of the respondent duck farmers and management practices followed in duck farming were the main focus of the present study. Most of the farmers were young having small family size with secondary level of education. Fifty per cent of the farmers had duck farming as their main business. Majority of the respondent were marginal farmers having a medium level of annual income. The overall management practices were good in both Bagmara and Tanore upazila. Most of the farmers have made comparatively low cost but durable tin-shed houses for their ducks. Majority of the farmers ensured sufficient floor space, proper ventilation, and required feed for their ducks. At the same time most of the farmers with partial idea about duck disease maintained cleaned atmosphere and followed regular vaccination program in their farm houses. It was found that highest proportion of the farmers disposed off their diseased/dead birds correctly. However, the findings of the present research indicate that duck farming has a great potentiality in this region. If the local Livestock Department or Nongovernment Organizations (NGOs) take initiatives for intensive training for the farmers then their management efficiency will be increased to a greater extent which can make duck farming a profitable enterprise in Bangladesh.

\section{References}

Bangladesh Bureau of Statistics (BBS) (2001). Bangladesh Population Census Report 2001: Community Series: Zila Rajshahi. Planning Div., Ministry of Planning, Government of the People's Republic of Bangladesh, Dhaka. P. 61-62.

Department of Fisheries and Livestock Information, Annual Livestock Compilation, June (2011). Dhaka: Ministry of Fisheries and Livestock, Government of the Peoples' Republic of Bangladesh. P. 102-111.

Finance Division, Bangladesh Economic Review (2010). Ministry of Finance, Government of the People's Republic of Bangladesh, Dhaka. P. 92-93.

Mahmud, MAA (1998). An Economic Analysis of Duck Raising in Some Selected Haor Areas of Kishorganj District. MS Thesis, Dept. Agril. Econ. Bang. Agril. Univ. Mymensingh, Bangladesh. P. 60-69.

Mendes AA, Gracia EA, RG Paz ICLA and Moreira J (2004). Effect of Stocking Densities and Season on Growth Performance, Environmental and Thermoregulatory Parameters and Carcass Yield of Broiler Chicken, Proc. Worl. Poult. Congr., 8-13 June 2004, Istanbul Convention Exhibition Centre, Istanbul, Turkey.

Mozumdar L, Farid KS, Ahmed JU and Rahman MW (2009). Broiler Farming: An Approach to Improve Rural Livelihood. J. Bangladesh Agril. Univ. 7: 395-402.

Pingel Heinz (2011). Waterfowl Production for Food Security. Lohman Information. 46: 3437.

Rahman MM, Khan MJ, Chowdhury SD and Akbar MA (2009). Duck Rearing System in Southern Coastal District of Bangladesh. Bang. J. Anim. Sci. 38: 132-141.

Roy BC (2000). Identification of Constraints of Raising Broiler of Small Flock Size and Determination of their Remadial Measures. MS Thesis, Dept. of Poultry Sci., Bang. Agri. Univ., Mymensingh, Bangladesh. P. 34-50. 